\title{
Study on Settlement Mechanism of Collective Labor Dispute in China
}

\author{
Qiuxia Tan ${ }^{1}$ \\ ${ }^{1}$ School of Law, University of Jinan (West Campus), Jinan, China \\ Correspondence: Qiuxia Tan, School of Law, University of Jinan (West Campus), No.336 nanxin west Road, \\ Jinan 250022, Shandong, China. E-mail: sl_tanqx@ujn.edu.cn
}

Received: March 12, $2014 \quad$ Accepted: March 27, $2014 \quad$ Online Published: May 28, 2014
doi:10.5539/jpl.v7n2p107
URL: http://dx.doi.org/10.5539/jpl.v7n2p107

This paper is a periodical achievement of a Shandong social sciences planning project and a project of law association of Shandong Province.

\begin{abstract}
More and more mass disturbances come into people's sight that are caused by contradiction between labor and capital, which highlights disharmony of the relationship between labor and capital in the reform and economic system and in the process of economic marketization and globalization. This arouses our legal consideration in construction of the settlement mechanism of collective labor dispute. We should flexibly call the traditional labor organization pattern, namely, the system of workers and staff congress, construct and improve the early warning mechanism of labor relationship and enhance the settlement mechanism of the current collective labor dispute.
\end{abstract}

Keywords: collective labor dispute, settlement mechanism, suggestion

\section{Preface}

Ever since the reform and opening up, the economy in China has gained a development with high speed. However, in the meanwhile, quite a lot of social problems come into being and the contradiction between labor and capital and the conflict between labor and capital is one of the most prominent social problems, especially the tide of strike that has occurred since 2010 in the Pearl River Delta, the Yangtze River Delta and the Northeastern China, etc. Just as some scholars mention, the significance of promulgation of such laws as "Labor Contract Law" is not that it has established a "milestone" in the legal history of the law, but has served as a link between the past and the future in the legal history of the law. It marks that individual adjustment of labor relationship has been almost completed in legal construction, and, meantime, has initiated a new departure of labor relationship in terms of collective adjustment. (Chang \& Qiu, 2011) Therefore, the settlement mechanism of collective labor dispute will be the focus of legislation and practice in the future. The stipulation related with collective consultation mechanism that has been drawn up recently is the evidence. Some areas have been aware that corresponding system and measures are necessary for settlement of collective labor dispute. (Note 1) Collective labor dispute has entered the vision of law as an important research subject and has become a hot topic in legal study.

So far as the settlement mechanism of collective labor dispute is concerned, as its settlement object is collective labor dispute, it has strong conflict features and inconsistent degree of organization. Also, this kind of dispute often gives rise to great social influences, the outcome of the settlement usually involves a large number of laborers, and the content of dispute often relates to such sensitive issues as wage and insurance. However, the law in Chinese has always treated individual labor relationship as the key of labor law adjustment. This forms the current settlement mechanism of labor dispute, namely, "one adjustment, one judgment and two trials" and "first judgment and then trial". Settlement mechanism of collective labor dispute is nothing more than a simple institutional framework of "collective consultation" and it still has legislative blankness in terms of the right of collective consultation. This causes a lot of collective labor disputes, in essence, to have no law to abide by and, thus, to be shown in the form of spontaneous collective action. Legal adjustment of labor relationship in the market economy is centered by collective labor relationship. The collective labor and capital conflicts that are being put on the stage continuously and domestically are a necessary trend of the market economic development. This, essentially, should have been attributed to intensification of collective labor dispute and this, objectively, calls for establishment and improvement of the settlement mechanism of collective labor dispute. 


\section{Summary of Studies on Settlement Mechanism of Collective Labor Dispute}

\subsection{From the Perspective of the Historical Development of Labor Relationship, Institutionalization of Workers' Collective Rights Is the Core Issue in Constructing and Improving Collective Labor Relationship}

In western countries with a mature market economy, whether regulation on the collective rights of workers is effective has a direct effect on whether the collective labor relationship can run in harmony. Let's take UK and US experiences as an example. From acknowledgement of the legal position of the trade union and construction of the collective consultation system to the historical process of constant adjustment on relative laws regarding the collective rights of workers, reconciling the collective dispute of labor and capital and the issue of conflict between labor and capital turns to be the fact that the government continuously modifies and improves the law and attempts to establish a new labor and capital gaming mechanism so as to achieve the purpose of coordinate labor and capital relationship (Ickens \& Hall, 2003; Deakin \& Njoya, 2009). Incompleteness of relative system regarding collective labor relationship gives rise to the immediate consequence that emergence of collective labor dispute has never come to an end. Bulei Chen (2009) points out that in the process of constructing the current labor system, out of the consideration of balancing the interests, the government does not exert all its efforts in the legislation and implementation of the labor rights, which results in the fact that the existing labor system has no way to, to a large extent, resolve the contradiction between labor and capital in collective labor dispute and, thus, mass disturbance occurs.

Fuxi Wang (2010) discovers in his statistics of previous studies that, collective labor dispute and mass disturbance break out in a concentrated way and have strong conflict and higher degree of organization. Xintian Shi (2010) concludes, the collective labor dispute of laborers reveals the dilemma of laborers in their struggle for fairness and justice in an economic transitional period. In addition to theoretical studies on collective labor dispute, there are also scholars who undertake empirical studies on collective labor dispute. Weimin Ding and Zhiping Qi (2008) discover in their observation on the labor relationship condition in China according to the data issued by the Ministry of Labour and Social Security, the number of collective labor disputes placed on file and the number of people involved also maintain a high speed of growth and are difficult in handling. Thus, often, a large majority of and even the whole laborers in an enterprise will be involved. Once the contradiction becomes intensified, it is quite likely to give rise to a chain reaction and evolve into a large scale collective labor dispute, which may impose great pressure on the government. Zhang Qiuhui and Guilan Yu (2010) detect in their study on the number of cases of labor disputes across the whole country with a time span from 1991 to 2007, collective dispute manifests a large scale ascending tendency. In view of this, they propose that if a collective dispute event fails to get appropriate handling, it might lead to a collective emergency incident.

In the presence of the continuous rise of the number of labor dispute and the phenomenon that different handling methods are adopted in collective labor disputes caused in signing a collective contract and carrying out a collective labor contract, Chang Kai (2004) proposed including disputes in signing a collective contract in the procedure of labor dispute settlement and protecting the collective bargaining right of laborers. Xiangchen Liu and Rong Zeng (2007), from the perspective of constructing a harmonious society, proposed adopting the mode of "de-politicization" in handling such collective labor dispute behaviors as strike, adjusting a collective labor dispute in a legal way and establishing the two major legal procedures of dispute expression mechanism and reaction mechanism of collective labor dispute. Jinyu $\mathrm{Wu}$ (2012), after reviewing the historical development and structure formation of enterprise labor dispute mediation committee, finds it incapable of handling a large quantity of collective labor dispute cases. However, Jin Gao (2011) suggests flexibly employing the traditional labor organization mode, namely, the system of workers and staff congress, and reducing contradictions between labor and capital by means of strengthening co-determination of labor and capital. Meanwhile, she suggests preventing and resolving collective labor disputes through the approaches of improving collective consultation, standardizing the institutionalization of collective behaviors and establishing the mediation mechanism of collective disputes. With a comparison of four collective labordispute cases, Yi Duan (2012) points out, action-based collective labor dispute is not regulated by the law and this type of disputes brings huge costs to both parties of labor and capital. After an analysis on the characteristics of collective lockout events, Yanyuan Cheng and Fuxi Wang (2012) point out, this type of events break out all of sudden and often lacks smooth consultation mechanism and emotional release channel. Thus, this type of events are likely to evolve into social public events and are difficult to handle. Cao Kean and Dongliang Zheng (2012) both mention that mass dispute in China is, first of all, reflected in the form of a collective event, and, then, in the form of consultation. In the current dispute settlement arrangement, the settlement mechanism of collective labor dispute is not perfect and improvement of the system and mechanism seems quite urgent. 


\section{Research Data and Research Method}

\subsection{Research Data}

This paper makes an analysis of the previous literature to retrieve both domestic and foreign literature related and makes a summary and conclusion of relevant data. In the interview research, the author collects the first hand data about collective labor dispute from the interview.

\subsection{Research Method}

This paper will make a comprehensive use of the case analysis method and apply "labor relationship pluralist theory" and "collective action theory" in economics and the "Alternative Dispute Resolution (ADR) theory" in law. The paper will mainly make a comprehensive use of social empirical method, comparative analysis and normative analysis. Social empirical analysis contains multiple methods and this research study will mainly adopt the interview method, participation-based observation method and literature analysis method.

\section{Status Quo of Collective Labor Dispute in China}

Statistical data about collective labor dispute started with implementation of "Enterprise Labor Dispute Processing Rule" issued by the State Council in 1993, providing objective data for the current condition of the settlement mechanism of collective labor dispute. In 2007, labor dispute arbitration institutions at all levels all over the country accepted and heard 350,000 cases of labor dispute which involved 650,000 laborers, including 13,000 collective labor disputes which involved 270,000 laborers. In 2008, labor dispute arbitration institutions at all levels all over the country accepted and heard 693,000 cases of labor dispute which involved 1,214,000 laborers, including 22,000 collective labor disputes which involved 503,000 laborers. In 2009, labor dispute arbitration institutions at all levels all over the country accepted and heard 684,000 cases of labor dispute which involved 1,017,000 laborers, including 14,000 collective labor disputes which involved 30,000 laborers. In 2010, labor dispute arbitration institutions at all levels all over the country accepted and heard 601,000 cases of labor dispute which involved 815,000 laborers, including 9,000 collective labor disputes which involved 212,000 laborers. (Note 2)

Through an analysis of the above data, we may get such a conclusion about collective labor dispute that whether in a whole case or in an individual case, collective labor disputes involves a large number of people. The number of people involved in collective labor dispute accounts for a large proportion of the total population involved in labor disputes in that very year and the proportion occupies almost $30 \%-40 \%$ each year. In the meantime, we also find that the number of cases of collective labor disputes and the population of laborers involved manifest, generally, a down trend except for the year 2008. This does not conform with the image that the academics have on collective labor dispute reported by news reports to occur frequently in the recent years. The statistic data are only the number of labor dispute cases entering arbitration that are obtained according to strict legal procedures, whereas collective consultation dispute, as one of the typical types of collective labor dispute, is naturally not included in the statistic data about the number of collective labor dispute. Thus, we get the above data that the number of collective labor disputes drops. If the number of collective labor disputes that have entered arbitration and have emerged through a variety of paths is added, together with the potential labor disputes that have not been manifested in an external form, the number of collective labor disputes at present will be largely higher than the statistic data. ( $\mathrm{Li}, 2009)$

Thus, we can find that, general collective disputes gradually decrease, namely, a large majority of laborers jointly participate in arbitration and litigation based on the same fact and reason. Nevertheless, collective contract disputes, in the essential sense, have increasingly occurred in the past few years, which can be evidenced from the news reports in the recent years although there has no formal data to prove that. For example, such collective action events as "Tonghua Incident" and "Linzhou Steel Incident" which happened in August 2009 and the strike tide represented by "Honda Event in the Nanhai Sea" which happened in the summer in 2010. These disputes have not been brought into the official statistic data by the government and, even in practice, collective bargaining which is the most typical solution mode of collective labor dispute is not acknowledged. This exactly proves deficiency of a normalized settlement mechanism of collective labor disputes in China.

Quite a lot of extant collective labor dispute cases are manifested as mass disputes primarily as a result of incompleteness of the existing law although they, essentially, are collective dispute cases. The so-called mass dispute means that laborers directly resort to such collective actions as strike, petition, march and demonstration instead of undergoing the current labor dispute settlement procedure of "one mediation, one arbitration and two trials", with the expectation to achieve the purpose of protecting their immediate interests. Mass labor dispute usually results in collective labor disputes that are not well resolved. (Zhou, 2008) 


\section{Several Suggestions to Construct the Settlement Mechanism of Collective Labor Dispute in China}

\subsection{Performing the Functions of the Congress of Workers and Staff}

Co-determination of labor and capital can be strengthened to decrease labor and capital contradictions and prevent occurring of collective labor dispute. The right of solidarity (the freedom right of association) is one of the basic rights of laborers, which is explicitly stipulated in "Universal Declaration of Human Rights", "Convention concerning Freedom of Association and Protection of the Right to Organize" by the International Labour Organization and "Constitution" and "Trade Union Law" in China. As an important organization to protect the rights and interests of laborers, the enterprise trade union organization has not changed its mode of being attached to the enterprise during the period of the planned economy. It is also deficient in due dependence in terms of personnel and financial resources. This causes its function of right protection and function of management to be interweaved together and it is forced to be in an awkward position. Furthermore, the organization and construction rate of trade union in enterprises, especially non-publicly owned enterprises has been low. "This adds much hypocrisy to the basic principles of the labor relationship of labor and capital autonomy". This requires to search for an effective mode of co-determination of labor and capital within the current institutional framework and to enable laborers to participate in a decision making of the enterprise and express their views and opinions by exercising the right to speak. Thus, in the face of the reality that the organization and construction rate of the trade union currently in China is low and the capacity of negotiation is weak, we may choose to take full advantage of the traditional labor organization of the congress of workers and staff as an alternative way of co-determination of labor and capital. It is stipulated in the Item Two of Article Four of "Labor Contract Law" that, in formulating, modifying or deciding rules and regulations or significant matters that directly involve the immediate interests of laborers, the employer should discuss together with the congress of workers and staff or the whole staff to propose a plan and come to a final determination after consultation on the basis of equality with the trade union or representatives of the staff. It is known from the stipulation that, the government has regarded as a formal procedure to discuss, consult and determine "rules and regulations or significant matters that involve the immediate interests of laborers" together with the congress of workers and staff or the whole staff. To emphasize the necessity of consultation by the wording "should" is exactly a tendency that we enable the congress of workers and staff to give adequate right of speaking to laborers and realize their expression of the immediate interests. Of course, compared with collective bargaining, coordination is far more than opposition in this mode of consultation. However, different enterprises have different degrees of capacity in providing workers with the opportunity to express their opinions, functioning of co-determination also depends on the degree of sincerity and efforts they make in consultation. In addition, stipulation on this kind of consultation mode at present was mostly made during the period of the planned economy. Thus, quite a lot of content can no longer adapt to the need of democratic administration of workers and staff at the current stage. It appears especially important to adapt to development of the society and economy, improve the legislation on the system of workers and staff congress and make unified and specific stipulation on the system.

\subsection{Establishing and Improving the Early Warning Mechanism of Labor Relationship}

It is necessary to put forth effort to exert the function of the labor dispute mediation committee of an enterprise to prevent collective labor dispute, get mastery of the first-hand signal of workers and staff, establish the system of labor dispute information messenger in an enterprise, place the focus of attention on daily production process, pay attention to the interest appeal of workers and staff and set up, at a local level, the system of notification on member information of the "three parties" (namely, government, trade union and enterprise) involved in labor relationship. (Tan, 2013) In the meantime, the departments of labor, petition letter, trade union and civil administration can jointly set up a social early warning indicator system to provide scientific evidence for decision making of the Party committee government and prevent the needy workers and staff from launching a large scale collective petition or mass disturbance as a consequence of the same problem. Under the circumstance when contradictions between labor and capital have not been highlighted, effective communication with the two parties of labor and capital and feasible suggestions for the two parties of labor and capital can realize the function of preventing contradictions between labor and capital.

\subsection{Improving the Settlement Mechanism of Collective Labor Dispute}

\subsubsection{Propelling the Reform of Separation of Arbitration and Trial}

It is stipulated in the Fifth Article in "Labor Dispute Mediation and Arbitration Law of the People's Republic of China" "The parties involved in a labor dispute may apply to the mediation organization for mediation under the circumstance that they are unwilling to negotiate, that they fail in a negotiation or that they are unwilling to 
fulfill the negotiation agreement; they may apply to the labor dispute arbitration committee for arbitration under the circumstance that they are unwilling to mediate, that they fail in a mediation or that they are unwilling to fulfill the mediation agreement; they may institute a legal proceeding to the people's court if disaffected with the arbitration decision, unless otherwise provided for in the law." Thus, it can be seen, arbitration is still a necessary procedure of a labor dispute. Nevertheless, as it turns out, this system of "voluntary mediation, one arbitration and two trials" has had some difficulty in coping with the increasingly complex collective labor disputes. Its complicated procedure and lengthy deadline is quite against timely solution of a dispute. As a necessary procedure, "one arbitration" is already overwhelmed as a consequence of "the large number of cases and the small number of people" and has become "a bottleneck" of the mediation. Besides, the dissatisfaction emotion of workers and staff can't get timely persuasion and treatment, which is also one of the most important factors in collective labor disputes. Therefore, in copying with a collective labor dispute case, it is necessary to carry out the system of separation of arbitration and trial and adopt the mode of "voluntary selection and either arbitration or trial" in a collective labor dispute, with the expectation that an appeal of workers and staff can get timely response and treatment and a contradiction can be resolved in the bud.

\subsubsection{Establishing a Labor Court}

With concentrated outbreak of collective labor disputes, the extant court trial organization is not capable of coping with the daily increasing labor disputes. At the litigation phase of a collective labor dispute, it is a must to establish, otherwise, a special labor court to be specialized in litigation affairs of collective labor dispute and make an independent judgment. It can set up principle, mode and time limit that are distinguished from treatment of an individual labor dispute. Meanwhile, an independent arbitration institution can be set up in the labor court which carries out voluntary arbitration and the system mode of "the court of second instance being the court of last instance".

\subsubsection{Setting up the Third-party Organization by Referring to Foreign Experiences}

As a mature market economy nation, UK has quite abundant experiences in mediation mechanism of labor dispute. The UK Advisory, Conciliation and Arbitration Service (ACAS) is an institution that plays the most important role in mediation and prevention of collective labor dispute. Established in September 1974, ACAS is a third party institution funded by the government that copes with labor dispute issues with a neutral, independent, impartial and fair principle. The primary mission of the institution is to prevent and resolve a collective dispute and establish a harmonious labor and capital relationship by means of providing independent and neutral service. In its specific service for enterprises, ACAS does not rigidly separate advice, conciliation and arbitration, but, instead, connects the three together in an organic way. In their advice and training service provided to the two parties of labor and capital, ACAS offers pertinent advice to both the employer and the trade union at the very beginning to enable the two parties to know how to prevent and avoid a labor and capital conflict and, thus, attain the effect of enhancing productivity and job satisfaction. In response to changes in the labor policy, ACAS also treats reduction of the economic burden of an enterprise and the nation as an important principle in its intervening in conciliation and arbitration of a collective labor dispute. (Chang \& Meng, 2012) Thereby, ACAS puts more emphasis on intervening as early as possible and provides service of professional support for conciliation of contradictions and conflicts between labor and capital. Establishment of this institution has resolved quite a large number of collective labor dispute cases for UK. Our country is also planning to establish such a third party organization as ACAS in UK to mediate collective labor dispute and coordinate labor relationship and make it a mediator and conciliator of labor and capital within the framework of relative laws regarding collective labor relationship and effectively resolve contradictions and even conflicts between labor and capital.

\subsubsection{Enlarging the Strength of Supervision on Enterprises to Alleviate Conflicts between Labor and Capital}

The institutional guarantee to resolve collective labor dispute is to enlarge the strength of supervision from the government, intensify construction of labor dispute mediation organization in enterprises, competent departments and regional areas and enable them to assume the obligation of antecedent intervening and mediation of a collective labor dispute. To this end, it is necessary to enforce the accountability system, carry out the principle of resolving a conflict between labor and capital on the spot and within a definite time, combine responsibility investigation and performance assessment and establish a new performance evaluation system.

\section{Concluding Remarks}

Conflict between labor and capital is a normal and necessary reflection of labor and capital relationship under the backdrop of the market economy, whereas collective labor dispute is a primary manifestation of labor and capital conflict and is also an important approach for laborers to maintain their rights and interests. In the presence of 
the complicated and various collective labor disputes at present in China, correct understanding of the settlement principle of collective labor dispute and establishment of a series of settlement mechanisms to adjust and coordinate collective labor dispute is a realistic requirement for appropriate resolution of the widely existing collective labor and capital conflicts and is also of long term significance to protect the legal rights and interests of laborers, promote establishment of a harmonious labor relationship and resolve social labor issues.

\section{References}

Chang, K., \& Meng, Q. (2012). Change in the Settlement System of Collective Labor Dispute in UK and Its Enlightenment on China. China Labour and Social Security News, (2).

Chang, K., \& Qiu, J. (2011). Transformation of Labor Relationship in China and Focus on Rule of Law in Labor - Talk as of Implementation of Labor Contract Law. Exploration and Free Views, (10).

Li, K. G. (2009). The Current Situation and Settlement of Individual Labor Dispute. In K. Chang (Ed.), Report of Contemporary Labor Relationship in China. China labour and Social Security Publishers

Tan, Q. X. (2013, June). Status Quo, Existing Problems and Improvement of Tripartite Consultation Mechanism in China. Journal of Politics and Law. http://dx.doi.org/10.5539/jpl.v6n2p125

Zhou, K. C. (2008). Study on the Concept, Classification and Procedure Application of Labor Dispute. In B. H. Dong (Ed.), Study on the Legal System of Settlement of Labor Dispute. Beijing: China Labour and Social Security Publishers.

\section{Notes}

Note 1. According to Shanghai Committee of the Chinese Kuomintang Revolutionary Committee, the government is supposed to lay high emphasis on the dynamic condition of collective labor and capital dispute within a district and construct an early warning system of collective labor dispute at the three levels of the municipal government, the district and the street within the sphere of the municipal city. In settlement of collective labor dispute, it is necessary to make a labor-capital policy with prevention being first with the international experiences. It will submit a collective proposal to the two sessions of Shanghai City in 2014 to suggest constructing an early warning mechanism for collective labor dispute in the area of Shanghai.

Note 2. Data from 2007 to 2010 are all extracted from Ministry of Human Resources and Social Security. See "Labor and Social Security Undertakings Statistical Bulletin".

\section{Copyrights}

Copyright for this article is retained by the author(s), with first publication rights granted to the journal.

This is an open-access article distributed under the terms and conditions of the Creative Commons Attribution license (http://creativecommons.org/licenses/by/3.0/). 